\title{
Terrifying Pain
}

National Cancer Institute

\section{Source}

National Cancer Institute. Terrifying Pain. NCI Thesaurus. Code C101167.

A sensation of discomfort or distress that is frightening or scary. 